\title{
Limitations of Neuroendoscopic Treatment for Pediatric Hydrocephalus and Considerations from Future Perspectives
}

\author{
Kenichi NiSHIYAMA, ${ }^{1}$ Junichi YOSHIMURA, ${ }^{1}$ and Yukihiko FUJII ${ }^{1}$ \\ ${ }^{1}$ Brain Research Institute, University of Niigata, Niigata, Niigata
}

\begin{abstract}
Neuroendoscopy has become common in the field of pediatric neurosurgery. As an alternative procedure to cerebrospinal fluid shunt, endoscopic third ventriculostomy has been the routine surgical treatment for obstructive hydrocephalus. However, the indication is still debatable in infantile periods. The predictors of late failure and how to manage are still unknown. Recently, the remarkable results of endoscopic choroid plexus coagulation in combination with third ventriculostomy, reported from experiences in Africa, present puzzling complexity. The current data on the role of neuroendoscopic surgery for pediatric hydrocephalus is reported with discussion of its limitations and future perspectives, in this review.
\end{abstract}

Key words: hydrocephalus, neuroeodoscopy, cerebrospinal fluid, pediatric, shunt

\section{Introduction}

The cerebrospinal fluid (CSF) shunt has long been the classic treatment for pediatric hydrocephalus. It can resolve nearly all forms of hydrocephalus, regardless of the etiology. It is a simple procedure that can aid in having a relatively normal life. However, its failure rate is significant. The reported rate of shunt malfunction in the first year of placement is approximately $30 \%$, and about $10 \%$ per year thereafter. The risk of infection is between $5 \%$ and $10 \%$. In addition, the high rates of shunt complication such as slit ventricle syndrome are unacceptable by current standards. Children with shunts are dependent on surgical maintenance throughout their lives. ${ }^{1-8)}$ Therefore, the advent of neuroendoscopy was received with enthusiasm. Endoscopic third ventriculostomy (ETV) has been a routine surgical practice for the past two decades and provides an alternative to the CSF shunt. It is a straightforward procedure for diversion of the CSF and does not require placing devices in children's bodies. The utility and safety of ETV have been proven for obstructive hydrocephalus that occur secondary to aqueductal stenosis. However, for other indications, it is necessary to examine the anatomy and etiology, as well as the patient's age. During follow-up after

Received December 11, 2014; Accepted January 22, 2015
ETV, late failure can occur and may lead to rapid deterioration. The aim of this report is to review the current data on the use of neuroendoscopy in children and to discuss the limitations and future perspectives regarding this procedure.

\section{Patient Selection and ETV in Infants}

ETV has two main purposes: to restore CSF communication between the ventricle and subarachnoid space and to reduce transmantle pulsatile stress by increasing compliance of the ventricular wall. ${ }^{9}$ Since the 1990s, patients with aqueductal stenosis have been considered ideal candidate for ETV. ${ }^{10,11)}$ ETV quietly developed into a common procedure, without any prospective randomized trials comparing its efficacy to that of the CSF shunt. In spite of strict patient selection, the overall ETV success rate does not exceed $80 \% .^{12-16)}$ However, as neuroendoscopic technology has evolved and pediatric neurosurgeons have gained experience with the procedure, the indications for ETV have broadened. For example, patients with hydrocephalus who had a previously failed shunt have become ETV candidates. The success rate of ETV for shunt malfunction is notable, around $80 \% .{ }^{17-20)}$ In recent years, the use of ETV to treat many pathological conditions has been debated. These include myelomeningocele, Chiari type 1 malformation, Dandy-Walker malformation, and previous meningitis or hemorrhage. ${ }^{14,19,21,22)}$ 
In infants, the benefits conferred by ETV may be considerable due to the high complication rate of CSF shunts. However, there are two concerns with the use of ETV in infants. The first is safety of the procedure, including the possibility of damage to the ventricular and cisternal structures during surgery, CSF leakage, or infection soon after surgery and late closure of the stoma with rapid deterioration. The second concern is that an infant successfully treated with ETV may be transformed from active hydrocephalus to an arrested type. These infants often have larger ventricles than children treated with CSF shunts. No study has attempted to correlate the larger ventricle size with any measurements of psychomotor development. According to reports from a multitude of international studies, the shunt independence rate ranges from $25 \%$ to $89 \% .{ }^{23-28)}$ Two-thirds of the reports suggested that success rate is dependent on age of the infant at the time of ETV. ${ }^{29-34)}$ To increase ETV success rates, greater accuracy of appropriate patients would be advised. However, because of the high rate of shunt failure and complication, ETV is sometimes preferred as a first-line treatment. Further, the range of what is defined as failure in this age group is very wide. A multicenter prospective randomized study on infants up to 2 years of age with no flow at the level of the aqueduct, named the International Infant Hydrocephalus Study (IIHS) is now under way. This study focuses primarily on the neurodevelopmental outcomes associated with different treatment paradigms at 5 years, and includes a comprehensive assessment of relevant risks and benefits. ${ }^{35)}$

\section{Failed ETV and Its Management}

ETV failure is a possible event. Although most failures from ETV occur in the early period, within a few days to 2 weeks following the procedure, late failure after many months may lead to rapid deterioration and even sudden death. A rapid increase in intracranial pressure caused by late obstruction of the stoma is typically regarded as the mechanism of failure. ${ }^{36-42)}$ Early failure is attributed to the incorrect surgical technique or different criteria in the selection of patients. However, the predictors of late failure are still unknown. Therefore, patients who have undergone successful ETV should be followed on an ongoing basis. Neurosurgeons should encourage patients and their parents to return as soon as possible if any adverse symptoms develop, because these may have severe consequences. ${ }^{43)}$ Setting the CSF reservoir concurrently with ETV is one option for the treatment of emergencies, even though it means implantation of a foreign material. In Japan, a follow-up magnetic resonance imaging (MRI) examination including sagittal $\mathrm{T}_{2}$-weighted images, cine-MRI, or constructive interference in steady state (CISS) is often scheduled to detect the CSF flow across the stoma. However, there is currently no evidence regarding whether the patients with no flow on MRI following ETV may be at a greater risk to develop clinical symptoms. For these patients, a repeat ETV may be performed immediately rather than close observation. In the literature, repeat ETV has a good success rate. ${ }^{32,44-49)}$ Therefore, this is one option for patients with a failed ETV, and it provides a means of even avoiding the CSF shunt.

\section{ETV vs. Aqueductoplasty}

Endoscopic aqueductoplasty (EAP) is a means to restore the physiological CSF dynamics. This procedure provides an alternative to ETV, because it avoids the risk of severe arterial bleeding. EAP has been performed in cases with membranous or short segmental occlusion of the sylvian aqueduct. However, the long-term results of EAP have not been as successful as one would expect. ${ }^{50-54)}$ EAP has been shown to fail frequently. Schroeder et al. reported a re-closure rate of $50 \%$, and proposed that one contributing factor to re-closure could be lower aqueductal CSF flow through the stoma than that following ETV. ${ }^{55,56)}$ In addition, aqueductoplasty is generally considered a riskier procedure due to the higher risk of injuring midbrain structures. It may lead to neurological deficits such as oculomotor or trochlear nerve palsy, Parinaud's syndrome, and periaqueductal syndrome. Therefore, ETV, which has higher long-term success rates and less risk, would be a better alternative for membranous, short segmental, and even tumor-related occlusion of the aqueduct. ${ }^{55,57)}$ However, the condition of isolated fourth ventricle (IFV) is an exception. Almost all patients with IFV have a medical history of hydrocephalus within first year of life, mostly post-infectious or post-hemorrhagic. Further, following shunt placement, they often experience complicated overdrainage with aqueductal stenosis. Aqueductoplasty could be a means of establishing CSF communication to the formerly isolated ventricular compartment; however, a stent is mandatory to keep this pathway open. EAP with a stent could be one choice in the endoscopic treatment of IFV. ${ }^{50,53,55,57,58)}$

\section{ETV vs. CSF Shunt in Children}

As described above, ETV has been widely applied for pediatric hydrocephalus as an alternative to the CSF shunt mainly in an attempt to avoid foreign body implantation and to better simulate physiological 
CSF dynamics. However, the results of CSF shunt have rarely been compared to ETV. According to the pediatric study by de Ribaupierre et al., the failure rate of ETV was $26 \%$ and that of ventriculoperitoneal (VP) shunt was $42 \%$ at 5 years follow-up. In a review of the literature, the same trend was seen in other studies. ${ }^{59)}$ Kulkarni et al. reported that the relative risk of ETV failure is initially higher than that for the CSF shunt. However, the risk became progressively lower at approximately 3 months following the procedure, and was approximately half the risk of shunt failure at 2 years. ${ }^{60)}$ The decrease in ventricle size is usually smaller and happens more slowly after ETV compared to shunt. Pediatric neurosurgeons are sometimes concerned about the relationship between these neuroimaging changes and neuropsychological outcomes. Hirsch reviewed that the postoperative intelligence quotient (IQ) was not significantly different in 70 patients with shunts vs. 44 who underwent percutaneous third ventriculostomy. ${ }^{61)}$ Other reports also have found similar results. ${ }^{62,63)}$ Recently, Kulkarni et al. reported that at 1 year following surgery, the quality of life and IQ scores were not significantly different between an ETV and a VP shunt group. ${ }^{64,65)}$

\section{Challenging Procedure of ETV + CPC}

There has been a resurgence in the technique of choroid plexus coagulation (CPC) in combination with ETV ever since this procedure was performed for African children with hydrocephalus of various etiologies in 2005. ${ }^{66-73)}$ Warf and colleagues highlighted that hydrocephalus with shunt dependency is inadvisable in developing countries because of limited access to medical centers in the event of shunt malfunction. In 2005, Warf and colleagues reported the results of a combined ETV + CPC trial performed mainly in infant with post-infectious hydrocephalus and in those with myelomeningocele. A total of 266 patients underwent ETV + CPC, whereas ETV alone was performed in 284 patients. The results demonstrated that the ETV + CPC increased the success rate in infants from $47 \%$ to $66 \%{ }^{66)}$ In 2008, they reported the long-term results of ETV + CPC in hydrocephalus with myelomeningocele. The intention-to-treat analysis showed a shunt independence rate of $76 \%$ in 338 infants, which was higher than the results of ETV alone reported in the literature. ${ }^{22,32,67)}$ Further analyses regarding ETV + CPC performed in patients with encephalocele, Dandy-Walker complex, and congenital aqueductal stenosis have been conducted using their database..$^{70-72)}$ The success rates achieved were between $70 \%$ and $80 \%$. However, all pediatric neurosurgeons should be cautious about the meaning of "success." In these reports, success usually referred to controlling raised intracranial pressure and avoiding an extra-cranial CSF shunt. Cognitive function was not the main outcome index. In addition, all these results have been reported from Africa. In the coming years, the challenge will be to see whether these results from Africa can be extrapolated to developed countries. ${ }^{74)}$ The main advantage of ETV + CPC was avoidance of a shunt in patients who were difficult to follow-up. In Africa, geographic and socioeconomic constraints reasons for poor follow-up. The low possibility of cognitive salvage or the high rate of shunt complications, such as holoprosencephaly or hydroanencephaly, may be further reasons in developed nations. Technically, Warf and colleagues used a steerable endoscope via a single burr hole, sometimes in combination with septostomy, and coagulated the bilateral choroid plexus from the foramen of Monro to the entrance of the temporal horn. ${ }^{66,73)}$ This procedure appeared to be safe in some cases of severely dilated ventricles. For Japanese neuroendoscopic surgeons, the flexible endoscope is more familiar than it is in other European nations. Nevertheless, almost all pediatric neurosurgeons still believe that the use of ETV + CPC in pediatric hydrocephalus needs further evaluation.

\section{Conclusion}

It is difficult to determine the best strategy for CSF diversion in pediatric hydrocephalus. ETV is one of the alternative procedures to the CSF shunt in conditions of obstructive hydrocephalus such as aqueductal stenosis. However, the preferred indications in infants have not been fully determined. The mechanisms and predictors of late ETV failure that might cause rapid deterioration are not still known. Recently, other clinical dilemmas, such as the use of ETV + CPC have arisen. Definition of the optimal indications, perfection of endoscopic techniques, developing strategies for follow-up, and considering socioeconomic constraints are required from pediatric neurosurgeons when selecting a surgical strategy in pediatric hydrocephalus.

\section{Conflicts of Interest Disclosure}

The authors declare that they have no conflicts of interest.

\section{References}

1) Aschoff A, Kremer P, Hashemi B, Kunze S: The scientific history of hydrocephalus and its treatment. Neurosurg Rev 22: 67-93; discussion 94-95, 1999 
2) Hoppe-Hirsch E, Laroussinie F, Brunet L, Sainte-Rose C, Renier D, Cinalli G, Zerah M, Pierre-Kahn A: Late outcome of the surgical treatment of hydrocephalus. Childs Nerv Syst 14: 97-99, 1998

3) Kestle J, Drake J, Milner R, Sainte-Rose C, Cinalli G, Boop F, Piatt J, Haines S, Schiff S, Cochrane D, Steinbok P, MacNeil N: Long-term follow-up data from the Shunt Design Trial. Pediatr Neurosurg 33: 230-236, 2000

4) Kestle JR: Pediatric hydrocephalus: current management. Neurol Clin 21: 883-895, vii, 2003

5) Renier D, Sainte-Rose C, Pierre-Kahn A, Hirsch JF: Prenatal hydrocephalus: outcome and prognosis. Childs Nerv Syst 4: 213-222, 1988

6) Sainte-Rose C, Piatt JH, Renier D, Pierre-Kahn A, Hirsch JF, Hoffman HJ, Humphreys RP, Hendrick EB: Mechanical complications in shunts. Pediatr Neurosurg 17: 2-9, 1991

7) Simon TD, Riva-Cambrin J, Srivastava R, Bratton SL, Dean JM, Kestle JR; Hydrocephalus Clinical Research Network: Hospital care for children with hydrocephalus in the United States: utilization, charges, comorbidities, and deaths. J Neurosurg Pediatr 1: 131-137, 2008

8) Williams MA, McAllister JP, Walker ML, Kranz DA, Bergsneider M, Del Bigio MR, Fleming L, Frim DM, Gwinn K, Kestle JR, Luciano MG, Madsen JR, Oster-Granite ML, Spinella G: Priorities for hydrocephalus research: report from a National Institutes of Health-sponsored workshop. J Neurosurg 107: 345-357, 2007

9) Greitz D: Radiological assessment of hydrocephalus: new theories and implications for therapy. Neurosurg Rev 27: 145-165; discussion 166-167, 2004

10) Cinalli G, Sainte-Rose C, Chumas P, Zerah M, Brunelle F, Lot G, Pierre-Kahn A, Renier D: Failure of third ventriculostomy in the treatment of aqueductal stenosis in children. J Neurosurg 90: 448-454, 1999

11) Hellwig D, Grotenhuis JA, Tirakotai W, Riegel T, Schulte DM, Bauer BL, Bertalanffy H: Endoscopic third ventriculostomy for obstructive hydrocephalus. Neurosurg Rev 28: 1-34; discussion 35-38, 2005

12) Cinalli G, Cappabianca P, de Falco R, Spennato P, Cianciulli E, Cavallo LM, Esposito F, Ruggiero C, Maggi G, de Divitiis E: Current state and future development of intracranial neuroendoscopic surgery. Expert Rev Med Devices 2: 351-373, 2005

13) Goumnerova LC, Frim DM: Treatment of hydrocephalus with third ventriculocisternostomy: outcome and CSF flow patterns. Pediatr Neurosurg 27: 149-152, 1997

14) Jones RF, Stening WA, Brydon M: Endoscopic third ventriculostomy. Neurosurgery 26: 86-91; discussion 91-92, 1990

15) Kim S-K, Wang KC, Cho BK: Surgical outcome of pediatric hydrocephalus treated by endoscopic III ventriculostomy: prognostic factors and interpretation of postoperative neuroimaging. Childs Nerv Syst 16: 161-168; discussion 169, 2000

16) Tisell M, Edsbagge M, Stephensen H, Czosnyka M, Wikkelsø C: Elastance correlates with outcome after endoscopic third ventriculostomy in adults with hydrocephalus caused by primary aqueductal stenosis. Neurosurgery 50: 70-77, 2002

17) Bilginer B, Oguz KK, Akalan N: Endoscopic third ventriculostomy for malfunction in previously shunted infants. Childs Nerv Syst 25: 683-688, 2009

18) Boschert J, Hellwig D, Krauss JK: Endoscopic third ventriculostomy for shunt dysfunction in occlusive hydrocephalus: long-term follow up and review. $J$ Neurosurg 98: 1032-1039, 2003

19) Cinalli G, Salazar C, Mallucci C, Yada JZ, Zerah M, Sainte-Rose C: The role of endoscopic third ventriculostomy in the management of shunt malfunction. Neurosurgery 43: 1323-1327; discussion 1327-1329, 1998

20) Nishiyama K, Mori H, Tanaka R: Changes in cerebrospinal fluid hydrodynamics following endoscopic third ventriculostomy for shunt-dependent noncommunicating hydrocephalus. J Neurosurg 98: 1027-1031, 2003

21) Siomin V, Cinalli G, Grotenhuis A, Golash A, Oi S, Kothbauer K, Weiner H, Roth J, Beni-Adani L, PierreKahn A, Takahashi Y, Mallucci C, Abbott R, Wisoff J, Constantini S: Endoscopic third ventriculostomy in patients with cerebrospinal fluid infection and/ or hemorrhage. J Neurosurg 97: 519-524, 2002

22) Teo C, Jones R: Management of hydrocephalus by endoscopic third ventriculostomy in patients with myelomeningocele. Pediatr Neurosurg 25: 57-63; discussion 63, 1996

23) Beems T, Grotenhuis JA: Is the success rate of endoscopic third ventriculostomy age-dependent? An analysis of the results of endoscopic third ventriculostomy in young children. Childs Nerv Syst 18: 605-608, 2002

24) Buxton N, Macarthur D, Mallucci C, Punt J, Vloeberghs M: Neuroendoscopy in the premature population. Childs Nerv Syst 14: 649-652, 1998

25) Garg A, Suri A, Chandra PS, Kumar R, Sharma BS, Mahapatra AK: Endoscopic third ventriculostomy: 5 years' experience at the All India Institute of Medical Sciences. Pediatr Neurosurg 45: 1-5, 2009

26) Idowu O, Doherty A, Tiamiyu O: Initial experience with endoscopic third ventriculostomy in Nigeria, West Africa. Childs Nerv Syst 24: 253-255; discussion 257, 2008

27) Koch D, Wagner W: Endoscopic third ventriculostomy in infants of less than 1 year of age: which factors influence the outcome? Childs Nerv Syst 20: 405-411, 2004

28) Sufianov AA, Sufianova GZ, Iakimov IA: Endoscopic third ventriculostomy in patients younger than 2 years: outcome analysis of 41 hydrocephalus cases. J Neurosurg Pediatr 5: 392-401, 2010

29) Baldauf J, Oertel J, Gaab MR, Schroeder HW: Endoscopic third ventriculostomy in children younger than 2 years of age. Childs Nerv Syst 23: 623-626, 2007

30) Drake JM: Endoscopic third ventriculostomy in pediatric patients: the Canadian experience. Neurosurgery 60: 881-886; discussion 881-886, 2007 
31) Hopf NJ, Grunert P, Fries G, Resch KD, Perneczky A: Endoscopic third ventriculostomy: outcome analysis of 100 consecutive procedures. Neurosurgery 44: 795-804; discussion 804-806, 1999

32) Kadrian D, van Gelder J, Florida D, Jones R, Vonau M, Teo C, Stening W, Kwok B: Long-term reliability of endoscopic third ventriculostomy. Neurosurgery 56: 1271-1278; discussion 1278, 2005

33) Oertel JM, Baldauf J, Schroeder HW, Gaab MR: Endoscopic options in children: experience with 134 procedures. J Neurosurg Pediatr 3: 81-89, 2009

34) Warf BC: Hydrocephalus in Uganda: the predominance of infectious origin and primary management with endoscopic third ventriculostomy. J Neurosurg 102(1 Suppl 1): 1-15, 2005

35) Sgouros S, Kulkharni AV, Constantini S: The International Infant Hydrocephalus Study: concept and rational. Childs Nerv Syst 22: 338-345, 2006

36) Drake J, Chumas P, Kestle J, Pierre-Kahn A, Vinchon M, Brown J, Pollack IF, Arai H: Late rapid deterioration after endoscopic third ventriculostomy: additional cases and review of the literature. $J$ Neurosurg 105: 118-126, 2006

37) Fabiano AJ, Doyle K, Grand W: Delayed stoma failure in adult communicating hydrocephalus after initial successful treatment by endoscopic third ventriculostomy: case report. Neurosurgery 66: E1210-E1211; discussion E1211, 2010

38) Hader WJ, Drake J, Cochrane D, Sparrow O, Johnson ES, Kestle J: Death after late failure of third ventriculostomy in children. Report of three cases. J Neurosurg 97: 211-215, 2002

39) Javadpour M, May P, Mallucci C: Sudden death secondary to delayed closure of endoscopic third ventriculostomy. Br J Neurosurg 17: 266-269, 2003

40) Lipina R, Palecek T, Reguli S, Kovarova M: Death in consequence of late failure of endoscopic third ventriculostomy. Childs Nerv Syst 23: 815-819, 2007

41) Mobbs RJ, Vonau M, Davies MA: Death after late failure of endoscopic third ventriculostomy: a potential solution. Neurosurgery 53: 384-385; discussion 385-386, 2003

42) Nigri F, Telles C, Acioly MA: Late obstruction of an endoscopic third ventriculostomy stoma by metastatic seeding of a recurrent medulloblastoma. J Neurosurg Pediatr 5: 641-644, 2010

43) Kulkarni AV, Shams I, Cochrane DD, McNeely PD: Does treatment with endoscopic third ventriculostomy result in less concern among parents of children with hydrocephalus? Childs Nerv Syst 26: 1529-1534, 2010

44) Feng H, Huang G, Liao X, Fu K, Tan H, Pu H, Cheng Y, Liu W, Zhao D: Endoscopic third ventriculostomy in the management of obstructive hydrocephalus: an outcome analysis. J Neurosurg 100: 626-633, 2004

45) Hellwig D, Giordano M, Kappus C: Redo third ventriculostomy. World Neurosurg 79(2 Suppl): S22. e13-e20, 2013

46) Koch D, Grunert P, Filippi R, Hopf N: Re-ventriculostomy for treatment of obstructive hydrocephalus in cases of stoma dysfunction. Minim Invasive Neurosurg 45: 158-163, 2002

47) Mohanty A, Vasudev MK, Sampath S, Radhesh S, Sastry Kolluri VR: Failed endoscopic third ventriculostomy in children: management options. Pediatr Neurosurg 37: 304-309, 2002

48) Siomin V, Weiner H, Wisoff J, Cinalli G, Pierre-Kahn A, Saint-Rose C, Abbott R, Elran H, Beni-Adani L, Ouaknine G, Constantini S: Repeat endoscopic third ventriculostomy: is it worth trying? Childs Nerv Syst 17: 551-555, 2001

49) Surash S, Chumas P, Bhargava D, Crimmins D, Straiton J, Tyagi A: A retrospective analysis of revision endoscopic third ventriculostomy. Childs Nerv Syst 26: 1693-1698, 2010

50) Cinalli G, Spennato P, Savarese L, Ruggiero C, Aliberti F, Cuomo L, Cianciulli E, Maggi G: Endoscopic aqueductoplasty and placement of a stent in the cerebral aqueduct in the management of isolated fourth ventricle in children. J Neurosurg 104: 21-27, 2006

51) da Silva LR, Cavalheiro S, Zymberg ST: Endoscopic aqueductoplasty in the treatment of aqueductal stenosis. Childs Nerv Syst 23: 1263-1268, 2007

52) Erşahin Y: Endoscopic aqueductoplasty. Childs Nerv Syst 23: 143-150, 2007

53) Sagan LM, Kojder I, Poncyljusz W: Endoscopic aqueductal stent placement for the treatment of a trapped fourth ventricle. J Neurosurg 105: 275-280, 2006

54) Schroeder HW, Oertel J, Gaab MR: Endoscopic aqueductoplasty in the treatment of aqueductal stenosis. Childs Nerv Syst 20: 821-827, 2004

55) Schroeder C, Fleck S, Gaab MR, Schweim KH, Schroeder HW: Why does endoscopic aqueductoplasty fail so frequently? Analysis of cerebrospinal fluid flow after endoscopic third ventriculostomy and aqueductoplasty using cine phase-contrast magnetic resonance imaging. J Neurosurg 117: 141-149, 2012

56) Schroeder HW, Schweim C, Schweim KH, Gaab MR: Analysis of aqueductal cerebrospinal fluid flow after endoscopic aqueductoplasty by using cine phasecontrast magnetic resonance imaging. J Neurosurg 93: $237-244,2000$

57) Fritsch MJ, Schroeder HW: Endoscopic aqueductoplasty and stenting. World Neurosurg 79(2 Suppl): S20.e15-e18, 2013

58) Fritsch MJ, Kienke S, Manwaring KH, Mehdorn HM: Endoscopic aqueductoplasty and interventriculostomy for the treatment of isolated fourth ventricle in children. Neurosurgery 55: 372-377; discussion 377-379, 2004

59) de Ribaupierre S, Rilliet B, Vernet O, Regli L, Villemure JG: Third ventriculostomy vs ventriculoperitoneal shunt in pediatric obstructive hydrocephalus: results from a Swiss series and literature review. Childs Nerv Syst 23: 527-533, 2007

60) Kulkarni AV, Drake JM, Kestle JR, Mallucci CL, Sgouros S, Constantini S; Canadian Pediatric Neurosurgery Study Group: Endoscopic third ventriculostomy vs cerebrospinal fluid shunt in the treatment of hydrocephalus 
in children: a propensity score-adjusted analysis. Neurosurgery 67: 588-593, 2010

61) Hirsch JF: Percutaneous ventriculocisternostomies in non-communicating hydrocephalus. Monogr Neurol Sci 8: 170-178, 1982

62) Sainte Rose C: Third ventriculostomy, in Manwaring KH, Crone KR (eds): Neuroendoscopy. New York, Mary Ann Liebert, pp 47-62, 1992

63) Tuli S, Alshail E, Drake J: Third ventriculostomy versus cerebrospinal fluid shunt as a first procedure in pediatric hydrocephalus. Pediatr Neurosurg 30: 11-15, 1999

64) Drake JM, Kulkarni AV, Kestle J: Endoscopic third ventriculostomy versus ventriculoperitoneal shunt in pediatric patients: a decision analysis. Childs Nerv Syst 25: 467-472, 2009

65) Kulkarni AV, Shams I, Cochrane DD, McNeely PD: Quality of life after endoscopic third ventriculostomy and cerebrospinal fluid shunting: an adjusted multivariable analysis in a large cohort. J Neurosurg Pediatr 6: 11-16, 2010

66) Warf BC: Comparison of endoscopic third ventriculostomy alone and combined with choroid plexus cauterization in infants younger than 1 year of age: a prospective study in 550 African children. J Neurosurg 103(6 Suppl): 475-481, 2005

67) Warf BC, Campbell JW: Combined endoscopic third ventriculostomy and choroid plexus cauterization as primary treatment of hydrocephalus for infants with myelomeningocele: long-term results of a prospective intent-to-treat study in 115 East African infants. J Neurosurg Pediatr 2: 310-316, 2008

68) Warf B, Ondoma S, Kulkarni A, Donnelly R, Ampeire M, Akona J, Kabachelor CR, Mulondo R, Nsubuga BK: Neurocognitive outcome and ventricular volume in children with myelomeningocele treated for hydrocephalus in Uganda. J Neurosurg Pediatr 4: 564-570, 2009

69) Warf BC, Campbell JW, Riddle E: Initial experience with combined endoscopic third ventriculostomy and choroid plexus cauterization for post-hemorrhagic hydrocephalus of prematurity: the importance of prepontine cistern status and the predictive value of FIESTA MRI imaging. Childs Nerv Syst 27: 1063-1071, 2011

70) Warf BC, Dewan M, Mugamba J: Management of Dandy-Walker complex-associated infant hydrocephalus by combined endoscopic third ventriculostomy and choroid plexus cauterization. J Neurosurg Pediatr 8: 377-383, 2011

71) Warf BC, Stagno V, Mugamba J: Encephalocele in Uganda: ethnic distinctions in lesion location, endoscopic management of hydrocephalus, and survival in 110 consecutive children. J Neurosurg Pediatr 7: 88-93, 2011

72) Warf BC, Tracy S, Mugamba J: Long-term outcome for endoscopic third ventriculostomy alone or in combination with choroid plexus cauterization for congenital aqueductal stenosis in African infants. J Neurosurg Pediatr 10: 108-111, 2012

73) Warf BC: Congenital idiopathic hydrocephalus of infancy: the results of treatment by endoscopic third ventriculostomy with or without choroid plexus cauterization and suggestions for how it works. Childs Nerv Syst 29: 935-940, 2013

74) Kulkarni AV, Riva-Cambrin J, Browd SR, Drake JM, Holubkov R, Kestle JR, Limbrick DD, Rozzelle CJ, Simon TD, Tamber MS, Wellons JC, Whitehead WE; Hydrocephalus Clinical Research Network: Endoscopic third ventriculostomy and choroid plexus cauterization in infants with hydrocephalus: a retrospective Hydrocephalus Clinical Research Network study. J Neurosurg Pediatr 14: 224-229, 2014

Address reprint requests to: Kenichi Nishiyama, $\mathrm{MD}, \mathrm{PhD}$, Brain Research Institute, University of Niigata, 1-757 Asahimachi, Chuo-ku, Niigata, Niigata 951-8585, Japan. e-mail: nishiken@d4.dion.ne.jp 